\title{
Pulmonary sleeve resection in locally advanced lung cancer using cryopreserved allograft for pulmonary artery replacement
}

\author{
Jean-Philippe Berthet, MD, ${ }^{\text {a,b,c }}$ Marc Boada, MD, ${ }^{\text {a }}$ Marina Paradela, MD, ${ }^{a}$ Laureano Molins, MD, PhD, ${ }^{a}$ \\ Stefan Matecki, MD, PhD, ${ }^{c}$ Charles-Henri Marty-Ané, $\mathrm{MD}, \mathrm{PhD},{ }^{\mathrm{b}}$ and Abel Gómez-Caro, $\mathrm{MD}, \mathrm{PhD}^{\mathrm{a}}$
}

\begin{abstract}
Background: During lobectomy, resection of pulmonary artery, followed by reconstruction or replacement with or without concomitant sleeve bronchial resection, is feasible in selected cases. We report morbidity, mortality, and technical issues in pulmonary artery replacement using a cryopreserved arterial allograft after sleeve resection for centrally located non-small cell lung carcinoma (NSCLC).
\end{abstract}

Methods: We reviewed clinical and pathologic data of patients who underwent arterial sleeve lobectomy with pulmonary artery replacement in our institution from 2007 to 2012.

Results: Of 178 centrally located NSCLCs, sleeve resections were performed in $92(51 \%)$, pneumonectomies in $33(18 \%)$, and lobectomies in $53(31 \%)$. Of the $32(34.7 \%)$ pulmonary) reconstructions (excluding tangential suture), $20(21.7 \%)$ were end-to-end anastomosis, $2(2.1 \%)$ were pericardial patch reconstructions, and 10 $(11 \%)$ were PA replacements. Clinical T staging was cT2a in 4 patients, cT2b in 3, cT3 in 2, and cT4 in 1. Four patients received concurrent induction chemoradiotherapy. Three patients underwent a double-sleeve right lobectomy. Cryopreserved allografts used were descending thoracic aorta $(\mathrm{n}=3)$ and pulmonary arteries $(\mathrm{n}=7)$. Complete resection (R0) was achieved in all patients. Final $\mathrm{N}$ staging was pN0 $(\mathrm{n}=4), \mathrm{pN} 1$ $(\mathrm{n}=5)$, and $\mathrm{pN} 2(\mathrm{n}=1)$. There was no operative mortality. Four patients had major morbidity, including 1 early conduit thrombosis treated by pneumonectomy completion. Graft patency, assessed by contrast-enhanced computed tomography scan, was $90 \%$. Mean follow-up was $25 \pm 14$ (range, $8-47$ ) months $(30 \%$ for $>36$ months). Overall 5-year survival was $66.7 \%$, and the estimated median disease-free survival was 42 months.

Conclusions: In central NSCLCs, conservative surgery using a cryopreserved arterial allograft to replace the pulmonary artery after extended segmental resection could avoid pneumonectomy in selected patients. (J Thorac Cardiovasc Surg 2013;146:1191-7)

Sleeve resection has several advantages over pneumonectomy for centrally located primary non-small cell lung carcinoma (NSCLC): fewer postoperative complications, ${ }^{1-4}$ reduced loss of pulmonary function, ${ }^{5}$ improved survival, ${ }^{1,3,5,6}$ better completion of adjuvant treatment, ${ }^{3}$ and higher quality of life. ${ }^{7}$ Sleeve resection is an appealing procedure for patients with impaired lung function or high operative risk. ${ }^{8}$ It has also been considered the better option to avoid the morbidity and mortality related to pneumonectomy. ${ }^{1,2,6,9,10}$ Depending on pulmonary) involvement, reconstruction ranges from tangential suture to patch reconstruction, end-to-end anastomosis, and, finally, PA replacement by a biologic or prosthetic conduit, ${ }^{11}$ which

\footnotetext{
From the General Thoracic Surgery Department, ${ }^{\mathrm{a}}$ Hospital Clinic, University of Barcelona, Barcelona, Spain; the Division of Thoracic Surgery, ${ }^{\mathrm{b}}$ Arnaud de Villeneuve University Hospital, Montpellier, France; and U1046, INSERM, ${ }^{c}$ Montpellier University 1, Montpellier University 2, Montpellier, France.

Disclosures: Authors have nothing to disclose with regard to commercial support.

Received for publication Feb 12, 2013; revisions received May 24, 2013; accepted for publication July 3, 2013; available ahead of print Aug 19, 2013.

Address for reprints: Jean-Philippe Berthet, MD, General Thoracic Surgery Department, Hospital Clinic, University of Barcelona, 170 Villarroel, Barcelona, Spain (E-mail: jeanphilippe.berthet@gmail.com).

$0022-5223 / \$ 36.00$

Copyright $(2013$ by The American Association for Thoracic Surgery

http://dx.doi.org/10.1016/j.jtcvs.2013.07.003
}

is indicated when the length between the 2 disease-free arterial PA stumps (proximal and distal) precludes reconstruction by end-to-end anastomosis. Numerous synthetic ${ }^{12}$ and autologous or heterologous biologic materials ${ }^{10,11,13,14}$ have been used in this procedure. The material selected depends on the location and extent of the arterial defect, together with the experience of the surgical team.

We report herein our experience in pulmonary sleeve resection in centrally located NSCLCs using a cryopreserved arterial allograft for PA replacement, alone or in association with a bronchial sleeve, as a suggested alternative to pneumonectomy.

\section{METHODS \\ Patients}

Of 178 patients with centrally located NSCLCs consecutively treated in our institution between January 2007 and December 2012, 92 (51.5\%) were amenable to circumferential arterial and/or bronchial sleeve resections, $33(18.5 \%)$ underwent pneumonectomy, and $53(30 \%)$ were finally resected by lobectomy (tangential PA resections and bronchial wedge were considered variations of standard lobectomy). PA reconstruction by autologous pericardial patch was performed in 2 cases, but end-to-end anastomosis was preferred when PA invasion was not amenable to tangential resection. Patients with extensive PA involvement, requiring cryopreserved allograft reconstruction, were included in the present study (Table 1). Extensive invasion was defined as full-thickness PA wall invasion close 


\section{Abbreviations and Acronyms \\ $\mathrm{CT}=$ computed tomography \\ NSCLC $=$ non-small cell lung carcinoma \\ PA $=$ pulmonary artery}

to the first division of the segment proximal to the origin of the superior segmental artery (A6) of the lower lobes, or immediately below it. The invasion was ascertained by the definitive pathologic examination. Three patients presenting with direct invasion of intrapericardial PA, requiring cardiopulmonary bypass, were excluded from the study.

All cases meeting oncologic and functional criteria of European Respiratory Society and European Society of Thoracic Surgeons guidelines ${ }^{15}$ were discussed by a multidisciplinary team (including L.M. and A.G-C.). Final staging was assessed according to the 2009 International Association for the Study of Lung Cancer staging system. Written informed consent was obtained for all patients. This study was approved by our institutional review board and ethics committee.

\section{Preoperative Assessment and Eligibility}

Preoperative evaluation included chest X-ray film, bronchoscopy, ${ }^{18} \mathrm{~F}$-fluoro-D-glucose positron emission tomography, and total-body contrastenhanced computed tomography (CT) scan. Clinical staging followed the revised TNM system, published in 2009, by the International Association for the Study of Lung Cancer.

In the case of clinical suspicion of $\mathrm{N} 2$ disease (lymph node short axis $>1$ $\mathrm{cm}$ on CT scan or ${ }^{18} \mathrm{~F}$-fluoro-D-glucose positron emission tomography uptake maximum standardized uptake value $>2.5$ ), histologic confirmation was assessed by the most appropriate invasive methods. If N2 disease was confirmed, neoadjuvant platinum-based chemotherapy and concurrent radiotherapy (45-60 Gy) were delivered to the tumor and mediastinal targets. Patients were considered operable in the presence of a clinical response on chest $\mathrm{CT}$ scan. When persistence of $\mathrm{cN} 1$ or $\mathrm{cN} 2$ disease was suspected, mediastinal restaging was performed. In case of progressive or N2 disease at restaging, surgical intervention was discarded.

Resection was considered functionally possible if the predictive postoperative forced expiratory volume in 1 second, calculated on the basis of spirometry and isotopic scanning, was more than $40 \%$ of the predicted value and there was no major hypoxemia $(<60 \mathrm{~mm} \mathrm{Hg})$ or hypercapnia $(>46 \mathrm{~mm} \mathrm{Hg}) .{ }^{15}$ All patients selected for PA replacement would have been expected to tolerate pneumonectomy.

\section{Surgical Technique}

All patients underwent double-lumen endotracheal intubation. The surgical approach was standard posterolateral thoracotomy. An intercostal muscle flap was harvested and preserved if bronchovascular reconstruction was planned. No irreversible procedure was performed before thoracic cavity exploration and confirmation of resectability by frozen section analysis. Oncologic and technical feasibility of sleeve resection and modality of PA reconstruction were assessed by the surgeon (A.G-C.) after proximal (most often intrapericardial) and distal control in the fissure. The proximal extension of the tumor always required controlling the PA origin, either proximal control posterior to the mobilized vena cava on the right side or proximal to the divided ligamentum arteriosum on the left side. Recurrent laryngeal and vagus nerves were identified routinely and preserved if oncologically possible.

The superior pulmonary vein was divided, allowing satisfactory exposure of the proximal PA. Systemic heparin sodium (5000 U/h) was intravenously administered before PA clamping (Figure 1, A). Vascular clamps were placed at the proximal and distal disease-free PA segment. En bloc resection of the tumor, upper lobe, and PA and, if required, adjacent structures (pericardium, chest wall, and bronchus circumference) was performed. The central extent of the PA resection was placed at least $5 \mathrm{~mm}$ away from the proximal clamp to ensure the ability to properly suture.

TABLE 1. Clinical characteristics, procedure, and outcomes in patients undergoing lobectomy with pulmonary artery replacement

\begin{tabular}{|c|c|c|c|c|c|c|c|}
\hline \multicolumn{2}{|c|}{ Patient } & \multicolumn{2}{|c|}{$\begin{array}{l}\text { Oncologic status } \\
\text { NSCLC }\end{array}$} & Surgery & \multicolumn{2}{|c|}{ Complications } & \multirow{2}{*}{$\begin{array}{l}\text { Outcome } \\
\text { Survival, } \\
\text { mo, status }\end{array}$} \\
\hline No. & Age/sex & TNM & $\begin{array}{c}\text { CRT } \\
\text { Gray timing, wk }\end{array}$ & $\begin{array}{c}\text { Surgery } \\
\text { lobectomy-CAA-associated } \\
\text { resection }\end{array}$ & $\begin{array}{c}\text { Major } \\
\text { complications }\end{array}$ & $\begin{array}{c}\text { Minor } \\
\text { complications }\end{array}$ & \\
\hline 1 & 70/M & cT2NOM0/pT2NOM0 & - & LUL-thoracic aorta allograft & - & - & 47, NED \\
\hline 2 & $59 / \mathrm{M}$ & cT2N0M0/pT3N1M0 & - & LUL-thoracic aorta allograft & - & $\begin{array}{l}\text { Sputum } \\
\text { retention }\end{array}$ & 42, NED \\
\hline 3 & $61 / \mathrm{M}$ & cT2NOM0/pT2NOM0 & - & LUL-pulmonary artery allograft & Pneumopathy & - & $\begin{array}{l}\text { 23, Deceased } \\
\text { (metastatic disease) }\end{array}$ \\
\hline 4 & $34 / \mathrm{F}$ & cT2N1M0/pT2N1M0 & - & LUL-thoracic aorta allograft & CAA thrombosis & - & 44, NED \\
\hline 5 & $63 / \mathrm{M}$ & cT4NOM0/pT4NOM0 & - & LUL-pulmonary artery allograft & - & - & 24, NED \\
\hline 6 & $47 / \mathrm{M}$ & cT2N2M0/pT2N1M0 & $\begin{array}{c}60 \text { Gy, } \\
8\end{array}$ & LUL-pulmonary artery allograft & - & - & 21, NED \\
\hline 7 & 68/M & cT2N2M0/pT2N2M0 & $\begin{array}{c}60 \text { Gy, } \\
8\end{array}$ & RUL (DS)-pulmonary artery allograft & - & - & 8, NED \\
\hline 8 & 78/M & cT3NOM0/pT3NOM0 & - & LUL-pulmonary artery allograft & $\begin{array}{l}\text { Empyema, } \\
\text { pneumopathy }\end{array}$ & $\begin{array}{l}\text { Sputum } \\
\quad \text { retention }\end{array}$ & $\begin{array}{l}\text { 6, Deceased } \\
\text { (retroperitoneal } \\
\text { hematoma) }\end{array}$ \\
\hline 9 & $61 / \mathrm{M}$ & cT3N2M0/pT3N1M0 & $\begin{array}{c}45 \text { Gy, } \\
12\end{array}$ & $\begin{array}{l}\text { RUL (DS)-pulmonary artery allograft, } \\
\text { superior vena cava replacement }\end{array}$ & - & - & 18, NED \\
\hline 10 & $58 / \mathrm{F}$ & cT2N2M0/pT2N1M0 & $\begin{array}{c}60 \text { Gy, } \\
8 \\
\end{array}$ & RUL (DS)-pulmonary artery allograft & Pneumopathy & - & 20, NED \\
\hline
\end{tabular}

Dashes indicate the patients did not receive radiotherapy. NSCLC, Non-small cell lung carcinoma; $C R T$, induction chemoradiotherapy; $C A A$, cryopreserved arterial allograft; $L U L$, left upper lobe; $N E D$, alive, no evidence of disease; $R U L$, right upper lobe; $D S$, double sleeve; $T N M$, tumor nodes metastasis classification. 

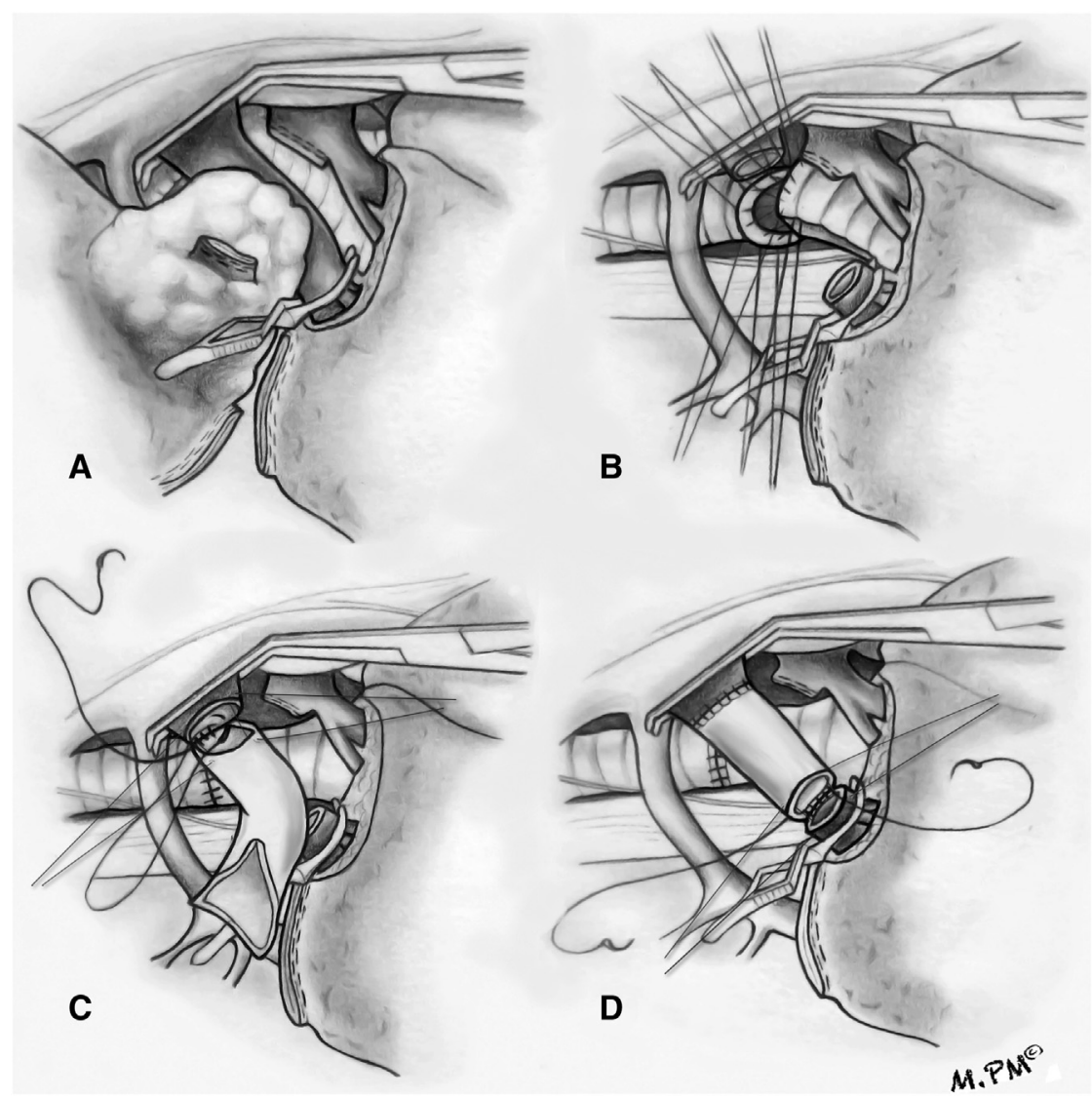

FIGURE 1. Surgical technique. A, Right upper lobe tumor involving the pulmonary artery (PA). Complete mobilization of the superior vena cava is needed before proximal PA control. To provide full exposure, the first steps are proximal and distal PA crossclamping using Satinsky and bulldog clamps, respectively, combined with division of the superior pulmonary vein. B, In the case of double sleeve, bronchial anastomosis is performed first, using a hybrid technique, ${ }^{3}$ and checked before PA reconstruction. C, Proximal "end-to-end" anastomosis between cryopreserved allograft and PA stump is performed with a nonabsorbable running suture. Corner sutures were used as a landmark to avoid twist. D, End-to-end distal anastomosis is performed after proximal PA reclamping, with or without distal clamp, and checked using the backflow.

The arterial- and bronchial-free margins were ascertained by frozen section analysis. After resection, if the distal disease-free PA stump was too short to allow both clamping and anastomosis, we removed the distal clamp because the surgical atelectasis of the remaining lobe progressively reduced the blood backflow (the lower pulmonary vein also might be clamped as needed). If complete resection required vascular and bronchial sleeves (double sleeve, $\mathrm{n}=3$ ), the bronchial anastomosis was performed first, using a hybrid technique ${ }^{3}$ (Figure 2,B).

\section{Cryopreserved Arterial Allografts}

Grafts originated from multiorgan donors whose PA and thoracic aorta were harvested, assessed, cryopreserved, and packed, as previously described, ${ }^{16}$ by the Transplant Service Foundation (Hospital Clinic, Barcelona, Spain). On removal from liquid nitrogen, the cryopreserved arterial allograft was placed in dry ice $\left(-80^{\circ} \mathrm{C}\right)$, sent to the operating room, and thawed (containers placed in a $37^{\circ} \mathrm{C}$ water bath for approximately 10 minutes). ${ }^{11,17}$ After washing in saline for 5 minutes, the allograft was then ready for implantation; $\mathrm{ABO}$ blood group and human leucocyte antigen group compatibility was not required. Morphologic criteria, based on preoperative chest CT scan (location, length, and diameter of the vessel to be replaced), were used to select the appropriate graft. Until 2008, we used the thoracic aorta because it was the only cryopreserved allograft available to us. When PA allografts became available in our tissue bank, they were routinely used.

\section{Arterial Allograft Implantation}

The anastomosis was performed under systemic heparinization and with irrigation using local heparinized saline. The systemic anticoagulation was not reversed with protamine, to avoid in situ thrombosis. The selected cryopreserved allograft was cut as short as possible, to avoid kinking of the graft during reexpansion of the pulmonary parenchyma. Before anastomosis, corner sutures were used as landmarks to avoid twist. End-to-end anastomosis between the proximal PA stump and the graft was performed first, using 5/0 polypropylene running sutures (Figure 1, C). To avoid excess length and kinking, the proper graft length was determined under blood pressure after proximal PA declamping and distal graft crossclamping. After proximal PA reclamping, the distal part of the cryopreserved allograft was then approximated to the distal PA stump with running sutures; the graft was flushed with heparinized saline and filled with blood backflow immediately before completing the suture (Figures $1, D$, and 2, $C$ ). The proximal clamp was then removed while a gentle ventilation of the remaining lobe quickly enhanced lung perfusion. A pedicled flap was used to wrap the bronchial stump/anastomosis and separate vascular and bronchial sutures.

\section{Postoperative Care Follow-up}

All patients were promptly extubated in the operating room (or in the intensive care unit). Patients received postoperative thromboembolic prophylaxis with low-molecular-weight heparin for 3 weeks. Survival, tumor 


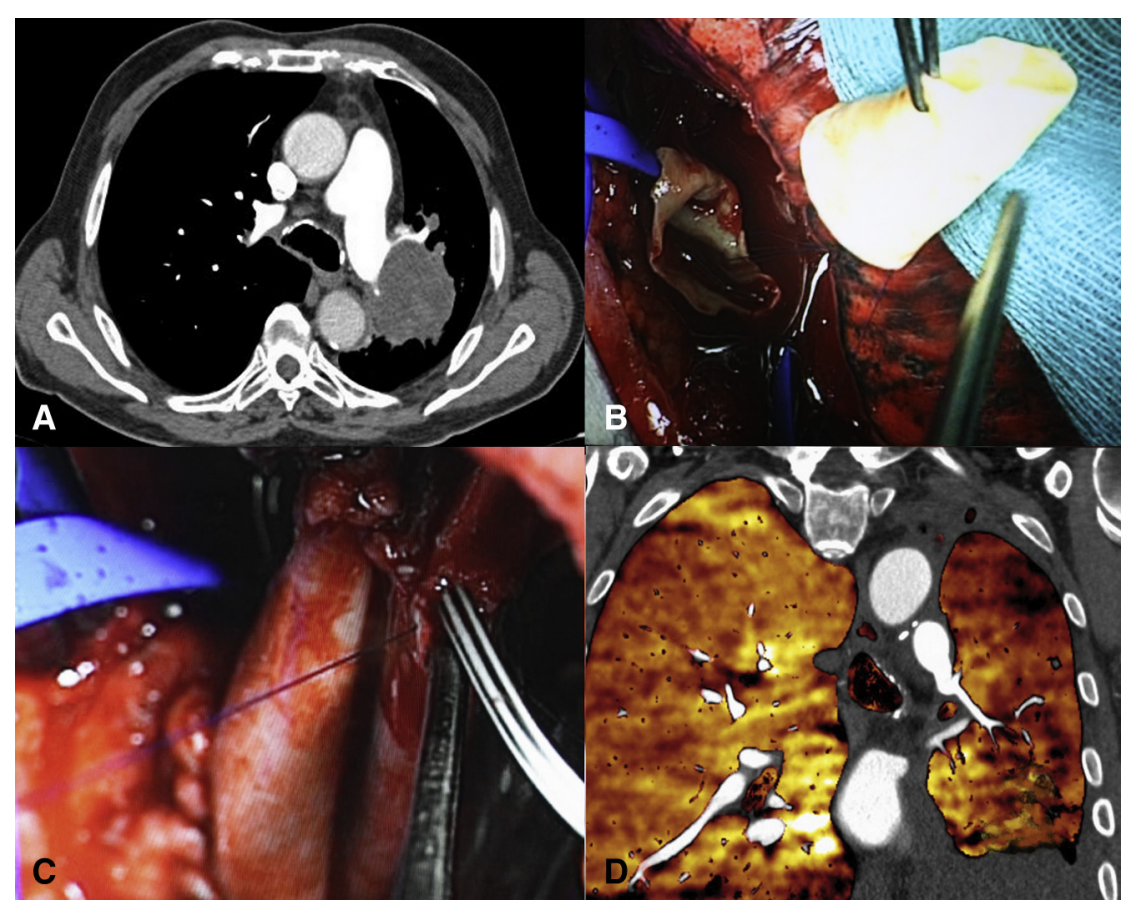

FIGURE 2. A, Chest computed tomography showing a central tumor with large invasion of the left pulmonary artery (PA). The PA involvement extended from the A1 origin to beneath the A6 branch. B, Left pulmonary artery proximal disease-free stump (5-mm length) and cryopreserved allograft are sutured together with a running polypropylene 5/0 suture. C, Cryopreserved allograft is filled with heparinized saline, before starting backflow and flushing out the air bubbles. Perfect matching is observed between the cryopreserved allograft and native PA diameters. Allograft length must be as short as is feasible to avoid kinking after lung reallocation in the thoracic cavity. D, Postoperative coronal color-code perfusion iodine map showing patent PA and branches into the well-expanded lower lobe.

recurrence, and graft patency were assessed during follow-up. A chest CT scan (with a bolus injection of contrast medium and multiplanar reconstruction to assess graft patency) and an additional abdominal and brain CT scan were scheduled every 3 months for the first 2 years, and every 6 months for 5 years thereafter.

Results are expressed as means \pm SDs. Survival probabilities from the surgery date until death were calculated using the Kaplan-Meier method, and estimated median disease-free survival (months) was calculated from the day of surgery until any oncologic event related to NSCLCs.

\section{RESULTS}

\section{Patient and TNM Status}

Between January 2007 and December 2012, 92 (51\%) of 178 central NSCLC tumors were amenable to circumferential arterial and/or bronchial sleeve resection, $33(18 \%)$ required pneumonectomy, and $53(31 \%)$ were resected by lobectomy. Reconstruction was performed in $32(35 \%)$ of the patients: $2(2.2 \%)$ by autologous pericardium patch, $20(22 \%)$ by end-to-end anastomosis, and $10(10.8 \%)$ by PA replacement by cryopreserved arterial allograft. Patients who underwent PA replacement were 8 men and 2 women, with a mean age of $62 \pm 12.4$ (range, 34-78) years (Table 1). Of these patients, 3 were older than 70 years, 7 were smokers, and 4 had a history of pulmonary disease. Tumor histologic features included 7 squamous cell carcinomas, 2 adenocarcinomas, and 1 atypical carcinoid tumor. The mean forced expiratory volume in 1 second was $2.2 \pm 0.4$ (range, 1.6-2.6) L; 4 patients had a forced expiratory volume in 1 second of less than $60 \%$. All patients had a PA patency despite massive tumor involvement.

In all cases, PA angioplasty or replacement was considered when analyzing the preoperative chest CT scan (Figure 2,A). During the same study period, a cryopreserved allograft was available in the operating room, but was not used in 23 cases because pneumonectomy or simpler PA reconstruction was achieved.

Preoperative staging identified cN0 disease in 5 patients and $\mathrm{cN} 1$ disease in 1; the indication for induction chemoradiotherapy was $\mathrm{N} 2$ disease in 4 patients. Clinical $\mathrm{T}$ staging was cT2a in 4 patients, cT2b in 3, cT3 in 2, and cT4 in 1 because of invasion of the superior vena cava. The mean size of tumors was $49.8 \pm 12.9$ (range, 30.5-75) mm. A chest $\mathrm{CT}$ scan after induction chemoradiotherapy showed partial responses in all cases.

\section{Type of Resection and Reconstruction}

Seven procedures were performed on the left side and 3 on the right side. Double-sleeve lobectomy was performed in 3 patients. A frozen section of the arterial wall was positive in 4 cases, requiring enlargement of the resection during the same operative procedure. During the same 
period, 6 patients assessed initially for PA replacement had a positive distal margin that precluded lobe-sparing surgery, and they underwent pneumonectomy. A pulmonary cryopreserved allograft was used in all but 3 procedures (patients 1,2, and 4, in whom PA was replaced by an aortic allograft). The mean procedure duration was $210 \pm 37$ (range, 177-287) minutes. Complete resection (R0) was achieved in all patients; final pNO was identified in 4 patients, pN1 in 5, and pN2 in 1 . Five patients $(2,4,5,7$, and 8 ) received postoperative chemotherapy.

\section{Postoperative Course}

There were no hospital deaths. Five patients $(2-4,8$, and 10) sustained morbidity, including 4 major and 2 minor complications (Table 1). Patient 4 required prompt completion pneumonectomy because of thrombosis of the allograft on the first postoperative day. Cryopreserved allograft patency was $90 \%$ (9/10). Postoperative pneumopathy associated with empyema required a chest tube placement in patient 8 . All patients required an intensive care unit stay, with a median of 3.6 (range, 1-23) days; the length of hospital stay was $11 \pm 6.7$ (range, 9-27) days.

\section{Follow-up}

No patients were lost to follow-up. The median time of observation was $25 \pm 14$ (range, 8-47) months (30\% for $>36$ months), and 7 patients are still alive with no evidence of recurrence (Figure 3). Patient 8 died of complications of a massive spontaneous retroperitoneal hematoma at 6 months after surgery, and patient 3 died of metastatic disease at 22 months (Table 1). A follow-up CT scan showed no signs of allograft infection, aneurismal degeneration, calcification, or surrounding tissue infiltration (Figure 2,D). Combined bronchial anastomosis (patients 7, 9, and 10) produced no early (kinking) or delayed abnormality (stenosis or granuloma formation). The Kaplan-Meier survival curve shows that overall 5-year survival was $66.7 \%$ (Figure 3 ); the median estimated disease-free survival was 42 months (patient 4 is excluded because of completion pneumonectomy).

\section{DISCUSSION}

The present study reports our experience with sleeve PA resection in patients with extensive PA invasion by NSCLC. Replacing the native vessel with a cryopreserved allograft demonstrated that this lung parenchyma-sparing procedure is feasible, with acceptable morbidity and no mortality.

Our group considers that avoidance of pneumonectomy is essential to decrease early postoperative mortality and improve the patient's quality of life and long-term outcomes. ${ }^{3,7,18}$ A meta-analysis by Ferguson and Lehman ${ }^{18}$ of early-stage NSCLC compared outcomes after 860 sleeve resections and 746 pneumonectomies. The sleeve group had better long-term survival and quality of life, regardless of underlying cardiopulmonary function. ${ }^{18} \mathrm{Ma}$ and coworkers ${ }^{19}$

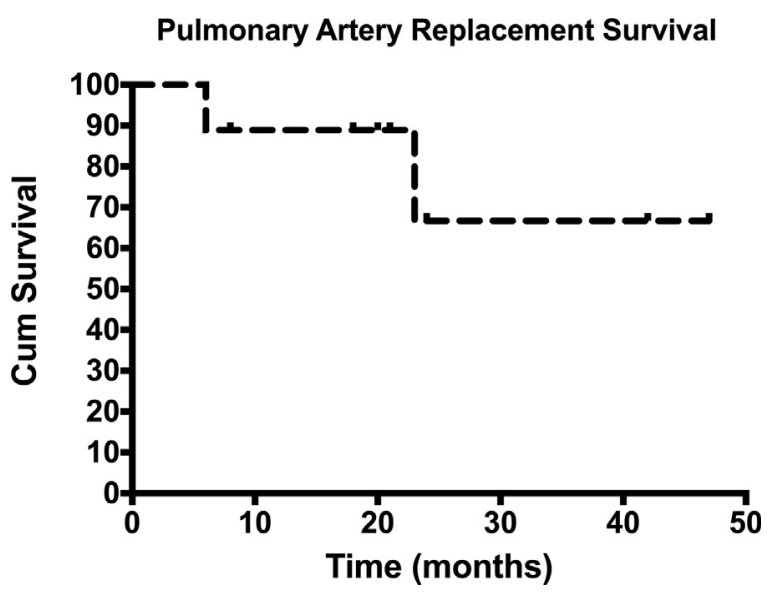

FIGURE 3. Kaplan-Meier curve for overall survival in 9 patients with patent pulmonary artery reconstruction.

concluded that, despite PA reconstruction, sleeve resection offered better long-term survival than did pneumonectomy. In the setting of major lung resection, the incidence of sleeve resection remains low, and is even lower in arterial reconstruction, with reported rates ranging from $1.5 \%$ to $3.7 \%{ }^{2,9,20}$ The most common arterial reconstructions described by surgical teams are tangential suture, angioplasty by patch, and endto-end anastomosis; the latter often represents the last effort before pneumonectomy is indicated (Table 2). When the extent of the PA defect precludes end-to-end anastomosis, some surgical teams planned PA replacement. ${ }^{11,16}$ However, experienced lung preservation surgery units either did not perform PA replacement ${ }^{6,8,20}$ or did so anecdotally. ${ }^{10}$

Prosthetic and biological substitutes have been used for this purpose. Prosthetic materials (polytetrafluoroethylene [Dacron]; Gore-Tex, WL Gore \& Associates, Flagstaff, Ariz $)^{12}$ have been occasionally used ${ }^{12,21}$; they are readily available, are easy to use, and can be adjusted perfectly to the PA diameter. The main issues of these substitutes are the high frequency of early thrombosis ${ }^{21}$ and potential infectious complications, especially in the case of double-sleeve resection, and the need for long-term anticoagulation therapy. Biologic substitutes are arterial or venous allografts or autologous pericardium conduits used with satisfactory results by Rendina and coworkers ${ }^{11}$ in 3 PA replacements. Homologous saphenous ${ }^{22}$ or pulmonary veins ${ }^{23}$ are possible alternatives. However, they require time-consuming intraoperative procedures, produce variable outcomes related to graft shrinkage or twisting, ${ }^{23}$ and are not always available.

Cryopreserved arterial allografts offer substantial advantages: availability in tissue banks, bacteriologic safety, and no need for anticoagulation therapy. Their ability to resist infection has been demonstrated by vascular surgeons in the routine use of cryopreserved allografts to address aortic prosthesis infection. The main drawbacks are related to availability and the need for an appropriate surgical structure, regular harvesting of organs, and coordination 
TABLE 2. Pulmonary artery reconstruction by different techniques (tangential suture, patch, end-to-end anastomosis, and replacement by conduits)

\begin{tabular}{|c|c|c|c|c|c|c|}
\hline Source & Period, y & No. & TS/P/EE/C & Conduit type & Mortality/PA thrombosis & 5-y Survival, $\%$ \\
\hline Rendina and colleagues, ${ }^{14}$ (1999) & 7 & 52 & $-/ 34 / 15 / 3$ & HPP/APP & $-/ 1$ & 38 \\
\hline Shrager and colleagues, ${ }^{27}$ (2000) & 7 & 33 & $19 / 11 / 3 / 0$ & - & $-1-$ & 48 \\
\hline Fadel and colleagues, ${ }^{2}(2002)$ & 20 & 11 & $-/-/ 11 /-$ & - & $1(0.7) /-$ & 52 \\
\hline Lausberg and colleagues, ${ }^{28}$ (2005) & 7 & 67 & 27/1/39/- & - & $1(1.5) /-$ & 43 \\
\hline Cerfolio and Bryant, ${ }^{20}$ (2007) & 8 & 42 & $31 / 7 / 4 /-$ & - & $1(2.3) /-$ & 60 \\
\hline Alifano and colleagues, ${ }^{9}$ (2009) & 8 & 93 & $90 /-/ 3 /-$ & - & $5(5.4) /-$ & 39.5 \\
\hline Venuta and colleagues, ${ }^{10}$ (2009) & 19 & 105 & $-/ 55 / 47 / 3$ & HPP/APP & $1(0.95) / 1$ & 44 \\
\hline Galetta and colleagues, ${ }^{13}$ (2012) & 11 & 47 & $31 / 10 / 4 / 2$ & HPP/APP & $2(4.2) /-$ & 39.2 \\
\hline Present study & 5 & 32 & $-/ 2 / 20 / 10$ & CAA & $1(2.9) / 1 \mathrm{EE}$ and $1 \mathrm{CAA}$ & 66 \\
\hline
\end{tabular}

Dashes indicate no conduit was used in these patients. $T S$, Tangential suture; $P$, patch; $E E$, end-to-end anastomosis; $C$, replacement by conduit; $P A$, pulmonary artery; $H P P$, heterologous pericardial patch; $A P P$, autologous pericardial patch; $C A A$, cryopreserved arterial allograft.

with scheduled surgery. Technically, when PA involvement has extended distally beneath the lower lobe segmental branches, interposition of a cryopreserved allograft (range, 2-4 cm) provides excellent PA reconstruction. In this case, it might be recommended to begin with the distal arterial anastomosis (usually the most difficult because of the smaller caliber and the need for reimplantation of segmental branches).

Compared with the report by Rendina and coworkers ${ }^{11}$ of $52 \mathrm{PA}$ reconstructions with 3 cases of PA replacement $(5.8 \%)$, our experience included $10(31.2 \%)$ of the cases. The more recent nature of our series may explain this higher rate of PA replacement, because tertiary referral centers increasingly develop aggressive policies of lung parenchymal sparing. ${ }^{3}$ Our experience of 7 isolated PA replacements after sleeve resections and 3 cases of double-sleeve resections corroborates another study by Rendina and coworkers, ${ }^{24}$ who reported the frequency of PA replacement (instead of end-to-end anastomosis or patch) in single PA resection without combined bronchial sleeve resection. In these cases, the long disease-free bronchial segment maintains both vascular edges at a far distance, inducing excessive tensioning of the arterial anastomosis. A forced end-to-end suture does not allow satisfactory PA reconstruction and may be responsible for PA or bronchial kinking, with subsequent risk of thrombosis. Moreover, PA suture performed under tension and with poor visibility of the arterial stumps, which may be weakened by neoadjuvant CRT, risks hemorrhagic complications or thrombosis. ${ }^{21,25}$

Early postoperative PA thrombosis after replacement generally leads to completion pneumonectomy. ${ }^{6,21}$ Read and coworkers ${ }^{21}$ reported on salvage surgical procedures in 5 of 11 patients, in whom PA reconstruction was attempted. It seems likely that the nature of the cryopreserved arterial allograft (thoracic aorta) was responsible for early thrombosis in patient 4, possibly because of differences in thickness and/or rigidity between the native PA and the cryopreserved allograft. Previous studies describing the use of a cryopreserved allograft in congenital heart surgery report a high rate of immunogenicity-related graft degeneration at long-term follow-up. ${ }^{26}$ Likewise, delayed aneurysms or stenoses when replacing systemic vessels are occasionally described as an argument against a cryopreserved allograft. However, clinically relevant immunogenicity or early degeneration has not been observed at our institution because these allografts were implemented for replacement of PA or other thoracic vessels. ${ }^{16}$

\section{CONCLUSIONS}

Our experience suggests that PA replacement using cryopreserved arterial allografts for circumferential defects after extended resection of centrally located NSCLCs is feasible, with acceptable morbidity. This procedure could avoid pneumonectomy in selected patients. The few patients do not permit a comparative study of survival and morbiditymortality; however, the initial results are encouraging.

We thank Alain Wurtz for revision and Elaine M. Lilly for her contribution to the developmental editing of the manuscript.

\section{References}

1. Deslauriers J, Gregoire J, Jacques LF, Piraux M, Guojin L, Lacasse Y. Sleeve lobectomy versus pneumonectomy for lung cancer: a comparative analysis of survival and sites or recurrences. Ann Thorac Surg. 2004;77:1152-6; discussion 1156.

2. Fadel E, Yildizeli B, Chapelier AR, Dicenta I, Mussot S, Dartevelle PG. Sleeve lobectomy for bronchogenic cancers: factors affecting survival. Ann Thorac Surg. 2002;74:851-8; discussion 858-9.

3. Gomez-Caro A, Garcia S, Reguart N, Cladellas E, Arguis P, Sanchez M, et al. Determining the appropriate sleeve lobectomy versus pneumonectomy ratio in central non-small cell lung cancer patients: an audit of an aggressive policy of pneumonectomy avoidance. Eur J Cardiothorac Surg. 2011;39:352-9.

4. Yamamoto K, Miyamoto Y, Ohsumi A, Kojima F, Imanishi N, Matsuoka K, et al. Sleeve lung resection for lung cancer: analysis according to the type of procedure. J Thorac Cardiovasc Surg. 2008;136:1349-56.

5. Okada M, Tsubota N, Yoshimura M, Miyamoto Y, Matsuoka H, Satake S, et al. Extended sleeve lobectomy for lung cancer: the avoidance of pneumonectomy. J Thorac Cardiovasc Surg. 1999;118:710-4.

6. Schirren J, Bolukbas S, Bergmann T, Fisseler-Eckhoff A, Trainer S, Beqiri S. Prospective study on perioperative risks and functional results in bronchial and bronchovascular sleeve resections. Thorac Cardiovasc Surg. 2009;57:35-41.

7. Balduyck B, Hendriks J, Lauwers P, Van Schil P. Quality of life after lung cancer surgery: a prospective pilot study comparing bronchial sleeve lobectomy with pneumonectomy. J Thorac Oncol. 2008;3:604-8.

8. Vogt-Moykopf I, Fritz T, Meyer G, Bulzerbruck H, Daskos G. Bronchoplastic and angioplastic operation in bronchial carcinoma: long-term results of a retrospective analysis from 1973 to 1983. Int Surg. 1986;71:211-20. 
9. Alifano M, Cusumano G, Strano S, Magdeleinat P, Bobbio A, Giraud F, et al. Lobectomy with pulmonary artery resection: morbidity, mortality, and long-term survival. J Thorac Cardiovasc Surg. 2009;137:1400-5.

10. Venuta F, Ciccone AM, Anile M, Ibrahim M, De Giacomo T, Coloni GF, et al. Reconstruction of the pulmonary artery for lung cancer: long-term results. J Thorac Cardiovasc Surg. 2009;138:1185-91.

11. Rendina EA, De Giacomo T, Venuta F, Ciccone AM, Coloni GF. Lung conservation techniques: bronchial sleeve resection and reconstruction of the pulmonary artery. Semin Surg Oncol. 2000;18:165-72.

12. Solli P, Spaggiari L, Grasso F, Pastorino U. Double prosthetic replacement of pulmonary artery and superior vena cava and sleeve lobectomy for lung cancer. Eur J Cardiothorac Surg. 2001;20:1045-8.

13. Galetta D, Solli P, Borri A, Gasparri R, Petrella F, Pardolesi A, et al. Bronchovascular reconstruction for lung cancer: does induction chemotherapy influence the outcomes? Ann Thorac Surg. 2012;94:907-13; discussion 913.

14. Rendina EA, Venuta F, De Giacomo T, Ciccone AM, Moretti M, Ruvolo G, et al. Sleeve resection and prosthetic reconstruction of the pulmonary artery for lung cancer. Ann Thorac Surg. 1999;68:995-1001; discussion 1002.

15. Brunelli A, Charloux A, Bolliger CT, Rocco G, Sculier JP, Varela G, et al. The European Respiratory Society and European Society of Thoracic Surgeons clinical guidelines for evaluating fitness for radical treatment (surgery and chemoradiotherapy) in patients with lung cancer. Eur J Cardiothorac Surg. 2009;36:181-4

16. Gomez-Caro A, Martinez E, Rodriguez A, Sanchez D, Martorell J, Gimferrer JM, et al. Cryopreserved arterial allograft reconstruction after excision of thoracic malignancies. Ann Thorac Surg. 2008;86:1753-61; discussion 1761.

17. Solanes N, Rigol M, Khabiri E, Castellà M, Ramírez J, Roqué M, et al. Effects of cryopreservation on the immunogenicity of porcine arterial allografts in early stages of transplant vasculopathy. Cryobiology. 2005;51:130-41.

18. Ferguson MK, Lehman AG. Sleeve lobectomy or pneumonectomy: optimal management strategy using decision analysis techniques. Ann Thorac Surg. 2003;76:1782-8.
19. Ma Z, Dong A, Fan J, Cheng H. Does sleeve lobectomy concomitant with or without pulmonary artery reconstruction (double sleeve) have favorable results for non-small cell lung cancer compared with pneumonectomy? a meta-analysis. Eur J Cardiothorac Surg. 2007;32:20-8.

20. Cerfolio RJ, Bryant AS. Surgical techniques and results for partial or circumferential sleeve resection of the pulmonary artery for patients with non-small cell lung cancer. Ann Thorac Surg. 2007;83:1971-6; discussion 1976-7.

21. Read RC, Ziomek S, Ranval TJ, Eidt JF, Gocio JC, Schaefer RF. Pulmonary artery sleeve resection for abutting left upper lobe lesions. Ann Thorac Surg. 1993;55:850-4; discussion 853-4.

22. Yoshimi F, Amemiya R, Asato Y, Koizumi S, Hasegawa H, Matsueda K, et al Pulmonary artery reconstruction using a great saphenous vein autograft in the treatment of bronchogenic cancer. Surg Today. 1994;24:570-3.

23. Puma F, Capozzi R, Daddi N, Ragusa M, Cagini L, Quintili A, et al Experience with the autologous pulmonary vein for pulmonary arterioplasty. Eur J Cardiothorac Surg. 2011;40:e107-11.

24. Rendina EA, Venuta F, Ciriaco P, Ricci C. Bronchovascular sleeve resection: technique, perioperative management, prevention, and treatment of complications. J Thorac Cardiovasc Surg. 1993;106:73-9.

25. Wada H, Okubo K, Hirata T, Hitomi S. Evaluation of cases with combined bronchoplasty and pulmonary arterioplasty for the treatment of lung cancer. Lung Cancer. 1995; 13:113-20.

26. Askovich B, Hawkins JA, Sower CT, Minich LL, Tani LY, Stoddard G, et al Right ventricle-to-pulmonary artery conduit longevity: is it related to allograft size? Ann Thorac Surg. 2007;84:907-11; discussion 911-2.

27. Shrager JB, Lambright ES, McGrath CM, Wahl PM, Deeb ME, Friedberg JS et al. Lobectomy with tangential pulmonary artery resection without regard to pulmonary function. Ann Thorac Surg. 2000;70:234-9.

28. Lausberg HF, Graeter TP, Tscholl D, Wendler O, Schafers HJ. Bronchovascula versus bronchial sleeve resection for central lung tumors. Ann Thorac Surg. 2005; 79:1147-52; discussion 1152 